\title{
Risk factors for renal toxicity after inpatient cisplatin administration
}

\author{
Elena Galfetti ${ }^{1}$, Alessandra Cerutti ${ }^{2}$, Michele Ghielmini ${ }^{3}$, Emanuele Zucca ${ }^{3}$ and Luciano Wannesson ${ }^{3 *}$ D
}

\begin{abstract}
Background: After several decades, cisplatin continues to be an essential drug for the treatment of several tumors, however, its potential nephrotoxicity is still a clinically relevant issue. Identification of predisposing factors for renal toxicity could be of value to warrant prophylactic measures.

Methods: We analyzed data from 198 patients with various tumor types, treated with cisplatin containing regimens in our regional cancer center in a two-years period. Assessed variables included age, gender, smoking status, alcohol consumption, tumor type, prior or concomitant anticancer treatment, cisplatin dose, time-interval between cycles, number of cycles, concomitant nephrotoxic drugs or radiotherapy and co-morbidities. We divided cisplatin nephrotoxicity in two categories: transient and permanent. Univariable and multivariable analyses were performed in order to define statistical associations.
\end{abstract}

Results: Cisplatin discontinuation rate was $27,7 \%$, of which, $8.1 \%$ was due to renal toxicity. A total of 74 and 21 patients developed transient and permanent nephrotoxicity, respectively. At univariable analysis cirrhosis ( $p=0.027)$, hypertension $(p=0.020)$, alcohol intake $(p=0.030)$ and number of cycles $\leq 4(p=0.002)$ were significantly associated with transient renal toxicity, while at the multivariable analysis, a statistical significance was detected for cirrhosis $(p=0.009)$, hypertension $(p=0.009)$ and a total number of cycles $\leq 4(p=0.003)$. Regarding permanent renal toxicity, a concomitant administration of NSAIDs was significant at univariable analysis $(p=0.002)$.

Conclusions: Relevant risk factors for the development of transient nephrotoxicity were defined. Patients presenting these baseline characteristics may require more frequent post-cycle check-up visits and hydration treatment should be guaranteed as soon as a reduction of creatinine clearance is detected.

Keywords: Cisplatin, Renal toxicity, Outpatient administration, Hypertension, Cirrhosis

\section{Background}

Cisplatin is a potent anticancer drug widely used for the treatment of several malignant tumors. One of the most relevant side effects of cisplatin is nephrotoxicity, that is very well-known since its introduction in 1978 and limits its use and efficacy $[1,2]$. Nephrotoxicity prevention has long been managed at the Istituto Oncologico della Svizzera Italiana (IOSI) with hospitalization and forced hydration protocols in order to guarantee a

\footnotetext{
* Correspondence: luciano.wannesson@eoc.ch

${ }^{3}$ Istituto Oncologico della Svizzera Italiana (IOSI), Oncology Clinic, Via Ospedale 12, 6500 Bellinzona, Switzerland

Full list of author information is available at the end of the article
}

minimum of forty-eight hours of intravenous perfusion. This modality, although associated with a low rate of renal toxicity in our hands, requires considerable resources at the expense of higher costs. For this reason we decided to develop an outpatient cisplatin administration program. Despite the worldwide use of cisplatin for more than 40 years and extensive research on nephrotoxicity mechanisms, we still have limited knowledge about the clinical factors influencing this phenomenon. The purpose of this study is to determine predisposing factors for cisplatin induced renal toxicity in order to allocate our patients with higher risk of renal toxicity to the inpatient strategy and patients at lower

(c) The Author(s). 2020 Open Access This article is licensed under a Creative Commons Attribution 4.0 International License, which permits use, sharing, adaptation, distribution and reproduction in any medium or format, as long as you give appropriate credit to the original author(s) and the source, provide a link to the Creative Commons licence, and indicate if changes were made. The images or other third party material in this article are included in the article's Creative Commons licence, unless indicated otherwise in a credit line to the material. If material is not included in the article's Creative Commons licence and your intended use is not permitted by statutory regulation or exceeds the permitted use, you will need to obtain permission directly from the copyright holder. To view a copy of this licence, visit http://creativecommons.org/licenses/by/4.0/ The Creative Commons Public Domain Dedication waiver (http://creativecommons.org/publicdomain/zero/1.0/) applies to the data made available in this article, unless otherwise stated in a credit line to the data. 
risk to the new outpatient cisplatin administration program.

\section{Methods}

We retrospectively analyzed the medical records of all adults patients $(N=198)$ treated with cisplatin-based chemotherapy for various types of tumors at our regional cancer center during the 2 years-period preceding the present analysis. Fourteen patients were excluded from the analysis due to incompleteness of data. In the case of patients treated with more than one cisplatincontaining line, only the earliest line was included in the analysis. We limited the cases to patients who received a dose of cisplatin below $100 \mathrm{mg} / \mathrm{m}^{2}$, because for patients who received doses $\geq 100 \mathrm{mg} / \mathrm{m}^{2}$, we decided to continue administering cisplatin upon the hospitalization-based modality. Cisplatin administration protocols complied with the recommendations of the European Society of Clinical Pharmacy published in 2008 [3].

\section{Selection of variables}

Variables potentially associated with nephrotoxicity were selected from previously published studies that investigated renal toxicity induced by cisplatin [4-12].. The following variables were recorded: age, gender, smoking status, alcohol abuse, body mass index (BMI) and tumor type. We also included previous cancer treatments, cisplatin dose per cycle, cumulative dose, type of administration (single day infusion versus dose divided into 2 or more days), time interval between cycles (in weeks), total number of cycles, other cytotoxic drugs administered with cisplatin and concomitant radiotherapy, potentially nephrotoxic drugs received during treatment with cisplatin such as NSAIDs, antibiotics (aminoglycosides, glycopeptides or other class of antibiotics); administration of drugs with nephroprotective potential (diuretics and mannitol); comorbidities (hypertension, diabetes mellitus, vasculopathy, heart disease, cirrhosis and COPD); and laboratory data such as serum albumin and electrolytes. Heart disease, alcohol abuse, cirrhosis and COPD were recorded as dichotomous variables, that is, present or absent, according to the data from the patient's records, because a more precise sub-classification or grading was not available for all cases.

\section{Assessment of toxicity}

To assess the influence of cisplatin on renal function in the short and long terms, we recorded the baseline creatinine level, the maximum creatinine value a few days after cisplatin administration and the best creatinine value after complete or partial recovery from cisplatin toxicity at variable time points. We calculated the estimated glomerular filtration rate (eGFR) according to the MDRD formula and the creatinine clearance by the
Cockroft-Gault formula. We defined renal toxicity as a decrease of $\geq 25 \%$ from baseline values according to both methods. If short-term renal function tests decreased more than $25 \%$ from baseline values, the renal toxicity was considered transient. Renal toxicity was considered permanent if long-term renal function tests remained over the $25 \%$ limit.

\section{Statistical analysis}

For the univariable analysis the statistical significance of the selected variables was calculated using Fisher's exact or chi-squared, as appropriated. Multivariable analysis was performed by stepwise linear regression with $p<$ 0.05 for variable-removal and $p<0.005$ for variableretention.

\section{Results}

\section{Patients characteristics}

Of the 184 patients, 106 were men and 78 women. Cancer types included head and neck (68 patients, 37\%), genitourinary (17 patients, 9.5\%), gynecological (23 patients, 13\%) pulmonary (28 patients, 15\%), gastrointestinal (24 patients, 13\%), hematological malignancies, mainly lymphoma and multiple myeloma (14 patients, $7.5 \%)$, breast (3 patients, $1.5 \%$ ), malignant melanoma (3 patients, $1.5 \%)$, thymoma ( 2 patients, $1 \%)$, adrenal (1 patient $0.5 \%$ ) and brain (1 patients, $0.5 \%$ ). Comorbidities included hypertension (30\%), diabetes $(5 \%)$, heart disease (6\%), vasculopathy (10\%), COPD (11\%), alcohol abuse (15\%) and liver cirrhosis (2\%) (Table 1).

Twenty-six patients (14\%) received iodinated radiological contrast around the date of administration of cisplatin. Five patients (3\%) received concomitant treatment with metformin, 13 (7\%) angiotensin converting enzyme and $28(15 \%)$ with NSAIDs. In addition, 3 patients received aminoglycoside antibiotics (2\%), 2 patients received glycopeptides (1\%) and 36 patients were treated with other antibiotics (19\%).

For 55 patients $(29.9 \%)$ cisplatin was not the first-line chemotherapy. Cisplatin was administrated alone (70 patients; $38 \%$ ), or associated to VP16 (26 patients, $14 \%$ ), taxanes (9 patients, $5 \%$ ), other agents (79 patients, $43 \%$ ) or radiation therapy (79 patients, $42 \%$ ). Cisplatin was administrated in 1 single day (166 patients, 90\%), in 2 consecutive days (6 patients, $3 \%$ ), in 3 or more consecutive days (12 patients, 7\%). The dose range per course was 10 to $100 \mathrm{mg} / \mathrm{m}^{2}$, with a mean of $69 \mathrm{mg} / \mathrm{m}^{2}(\mathrm{SD}+/-25)$. The range of cumulative doses remained between 40 and $490 \mathrm{mg} / \mathrm{m}^{2}$ (mean $219 \mathrm{mg} / \mathrm{m}^{2}$, SD $+/-91$ ). Total numbers of cycles ranged from 1 to 8 , with a mean 3.32 cycles. A total of 611 cisplatin administrations were recorded in the study population (Table 2 ). 
Table 1 Patient's characteristics

\begin{tabular}{|c|c|}
\hline & $\mathrm{N}$ of Patients (\%) \\
\hline \multicolumn{2}{|l|}{ Sex } \\
\hline Male & $106(58)$ \\
\hline Female & $78(42)$ \\
\hline \multicolumn{2}{|l|}{ Tumor Type } \\
\hline Head and neck & $68(37)$ \\
\hline Genitourinary & $17(9,5)$ \\
\hline Gynecological & $23(13)$ \\
\hline Pulmonary & $28(15)$ \\
\hline Gastrointestinal & $24(13)$ \\
\hline Hematological & $14(7,5)$ \\
\hline Breast & $3(1,5)$ \\
\hline Malignant melanoma & $3(1,5)$ \\
\hline Thymoma & $2(1)$ \\
\hline Endocrine & $1(0,5)$ \\
\hline CNS & $1(0,5)$ \\
\hline \multicolumn{2}{|l|}{ Co morbidity } \\
\hline Hypertension & $54(30)$ \\
\hline Diabetes & $10(5)$ \\
\hline Cardiopathy & $12(6)$ \\
\hline Vasculopathy & $19(10)$ \\
\hline COPD & $21(11)$ \\
\hline Alcohol abuse & $28(15)$ \\
\hline Liver Cirrhosis & $4(2)$ \\
\hline \multicolumn{2}{|l|}{ Drugs and other agents } \\
\hline ICM during cisplatin & $26(14)$ \\
\hline Metformin & $5(3)$ \\
\hline ACE-Inhibitor & $13(7)$ \\
\hline NSAID & $28(15)$ \\
\hline Aminoglycosides & $3(2)$ \\
\hline Glycopeptides & $2(1)$ \\
\hline Others antibiotics & $36(19)$ \\
\hline
\end{tabular}

Legend: CNS central nervous system, COPD Chronic obstructive pulmonary disease, ICM lodinated contrast media, NSAID Non steroidal anti-inflammatory drug

\section{Renal toxicity}

Cisplatin treatment was discontinued in 51 cases (27.7\%) of which $15(8.1 \%)$ were due to renal toxicity. Baseline mean eGFR was $99.69 \mathrm{ml} / \mathrm{min}$ (SD +/-26.61). Mean eGFR was reduced to $79.32 \mathrm{ml} / \mathrm{min}$ (SD +/-30.88) in the short-term after cisplatin administration and recovered to a mean of $98.29 \mathrm{ml} / \mathrm{min}(\mathrm{SD}+/-30.75)$ in the long-term period. Consequently, in the present model, the short-term values represent the transient cisplatin nephrotoxicity; while the long-term values represent the permanent cisplatin toxicity. 74 patients developed transient nephrotoxicity and 21 patient remained with permanent renal function impairment.

The following variables were found to be significantly associated with transient renal toxicity at univariable
Table 2 Cisplatin-administration characteristics

\begin{tabular}{ll}
\hline & N of Patients (\%) \\
\hline Previous chemotherapy & $55(29.9)$ \\
Co-Administration & \\
Cisplatin alone & $70(38)$ \\
VP-16 & $26(14)$ \\
Taxanes & $9(5)$ \\
Other agents & $79(43)$ \\
RT & $79(43)$ \\
Days of administration & \\
1 day & $166(90)$ \\
2 days & $6(3)$ \\
3 or more & $12(7)$ \\
Cisplatin dose per cycle & \\
Range & $10-100 \mathrm{mg} / \mathrm{m} 2$ \\
Mean & $69 \mathrm{mg} / \mathrm{m} 2$ \\
Cumulative dose (Range) & $40-490 \mathrm{mg} / \mathrm{m} 2$ \\
$\mathrm{~N}$ of administrations (Mean) & 3.32 \\
\hline Legend: $N$ Number, $R T$ Radiotherapy, VP-16=Etoposide
\end{tabular}

analysis: cirrhosis $(p=0.027)$, hypertension $(p=0.020)$, alcohol abuse $(p=0.030)$, number of total cycles $\leq 4 \quad(p=$ 0.002 ) (Table 3). At multivariable analysis, statistical significance was detected for cirrhosis $(p=0.009)$, hypertension $(\mathrm{p}=0.009)$ and a number of cycles $\leq 4 \quad(p=$ $0.003)$, constituting strong predictors of renal toxicity (Table 4).

Regarding permanent renal toxicity only concomitant use of NSAIDs was significant at univariable analysis $(p=0.002)$ (Table 5). We were not able to define a multivariable model for late toxicity due to a very low number of events.

\section{Discussion}

The aim of this study was to identify risk factors predisposing to renal toxicity due to cisplatin in order to better select those patients that could be safely treated in an outpatient basis with this cytotoxic drug.

A study conducted by de Jongh and colleagues determined an association of cisplatin renal toxicity and older age, female gender, smoking, hypoalbuminemia, and paclitaxel co-administration [4]. Another study conducted by Anand et al. suggested older age, alcohol intake and renal radiation as significant factors related to nephrotoxicity [5]. Serum albumin, metoclopramide and phenytoin were detected as possible factors affecting renal function at multivariable analysis by Stewart et al. [6]. Daugaard et al. showed that renal toxicity is dose dependent $[7,8,13]$.

Other factors associated with significant decrease in eGFR include the frequency of administration, the 
Table 3 Factors associated to transient renal toxicity at univariable analysis

\begin{tabular}{|c|c|c|c|c|c|}
\hline & $\mathrm{N}(\%)$ & $p$-value & & $N(\%)$ & $p$-value \\
\hline Sex & & & Yes & $29(54)$ & \\
\hline Male & $42(40)$ & 0.91 & Cirrhosis & & \\
\hline Female & $32(42)$ & & No & $70(40)$ & 0.015 \\
\hline Smoke & & & Yes & $4(100)$ & \\
\hline No & $33(42)$ & 0.81 & Hypoalbuminemia & & \\
\hline Yes & $26(41)$ & & No & $49(45)$ & 0.40 \\
\hline Former Smokers & $12(36)$ & & Yes & $10(55)$ & \\
\hline Alcohol abuse & & & Mannitol & & \\
\hline No & $58(38)$ & 0.02 & No & $49(43)$ & 0.92 \\
\hline Yes & $16(61)$ & & Yes & $23(42)$ & \\
\hline Diuretics & & & NSAID & & \\
\hline No & $36(34)$ & 0.14 & No & $58(38)$ & 0.06 \\
\hline During Cisplatin & $32(48)$ & & Yes & $16(61)$ & \\
\hline Before or after Cisplatin & $6(54)$ & & Number of cycles $\leq 4$ & & \\
\hline ACE Inhibitor & & & No & $19(27)$ & 0.002 \\
\hline No & $68(40)$ & 0.70 & Yes & $55(50)$ & \\
\hline
\end{tabular}

Yes

$6(46)$

Metformin

No

Yes

ICM

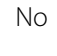

Yes

Obesity

No

Yes

Diabete

No

Dyslipidemia

No

Yes

Cardiopathy

No

Yes

Vasculopathy

No

Yes

COPD

No

Yes

Hypertension

No
70 (40)

4 (80)

65 (42)

9 (35)

8 (38)

$6(75)$

68 (40)

$6(60)$

63 (40)

11 (52)

70 (41)

4 (33)

68 (42)

$6(32)$

65 (40)

9 (47)

45 (35)
Table 3 Factors associated to transient renal toxicity at univariable analysis (Continued)

COPD Chronic obstructive pulmonary disease, $I C M$ lodinated contrast converting enzyme inhibitor, $N$ Number of patients

cumulative dose [10], concomitant use of aminoglycoside antibiotics [11] and other nephrotoxic drugs such as NSAIDs or iodinated contrast [3]. Comorbidities as hypertension, diabetes mellitus and ischemic heart disease also predispose patients to renal function impairment [12]. We found that in our patient population liver cirrhosis, hypertension and a number of cycles $\leq 4$ were strong independent predictors for transient renal toxicity. However, we were not able to identify independent predictors of permanent toxicity, probably due to a low number of patients (12\%) who developed a long-term eGFR decrease. It is important to note that a permanent renal function impairment defined as persistent decrease of eGFR $\geq 25 \%$ from baseline do not necessarily imply the development of chronic renal failure; this is particularly true for those patients with high eGFR at baseline. Even if predicting permanent cisplatin toxicity appears to be a more relevant objective, predicting transient toxicity may also have a valuable role for example to envisage those patients who may not be able to complete a

Table 4 Multivariable analysis of potential nephrotoxic risk factors according to the univariable analysis

\begin{tabular}{llll}
\hline & Coef. & $95 \%$ confidence interval & $p$-value \\
\hline Hypertension & 0.20 & $0.05-0.35$ & $\mathbf{0 . 0 0 9}$ \\
Cirrhosis & 0.63 & $0.16-1.10$ & $\mathbf{0 . 0 0 9}$ \\
Number of cycle $\leq 4$ & -0.21 & $-0.35--0.07$ & $\mathbf{0 . 0 0 3}$ \\
\hline
\end{tabular}


Table 5 Factors associated to permanent renal toxicity at univariable analysis

\begin{tabular}{lcc}
\hline & $N(\%)$ & $p$-value \\
\hline Sex & & \\
Male & $13(13)$ & 0.60 \\
Female & $8(10)$ & \\
Smoke & &
\end{tabular}

$\begin{array}{ll}\text { No } & 6(8) \\ \text { Yes } & 12(20) \\ \text { Former Smokers } & 2(6) \\ \text { Alcohol } & \end{array}$

$\begin{array}{ll}\text { No } & 18(12) \\ \text { Yes } & 3(12)\end{array}$

Diuretic

$\begin{array}{ll}\text { No } & 10(10) \\ \text { During Cisplatin } & 10(16) \\ \text { Before of after Cisplatin } & 1(9) \\ \text { ACE-Inhibitor } & \end{array}$

$\begin{array}{ll}\text { No } & 20 \\ \text { Yes } & 1(7) \\ \text { Metformin } & \end{array}$

$\begin{array}{ll}\text { No } & 20(12) \\ \text { Yes } & 1(20) \\ \text { ICM } & \\ \text { No } & 17(11) \\ \text { Yes } & 4(15) \\ \text { Obesity } & \\ \text { No } & 1(5) \\ \text { Yes } & 1(12) \\ \text { Dyslipidemia } & \end{array}$

$\begin{array}{ll}\text { No } & 16(10) \\ \text { Yes } & 5(23)\end{array}$

Diabetes

$\begin{array}{ll}\text { No } & 20(12) \\ \text { Yes } & 1(10) \\ \text { Cardiopathy } & \\ \text { No } & 21(13) \\ \text { Yes } & 0(0) \\ \text { Vasculopathy } & \\ \text { No } & 18(11) \\ \text { Yes } & 3(15) \\ \text { COPD } & \\ \text { No } & 18(11) \\ \text { Yes } & 3(15)\end{array}$

Hypertension
Table 5 Factors associated to permanent renal toxicity at univariable analysis (Continued)

\begin{tabular}{lll}
\hline & $N(\%)$ & p-value \\
\hline Yes & $9(16)$ & \\
Cirrhosis & & \\
No & $20(11)$ & 0.42 \\
Yes & $1(25)$ & \\
Hypoalbuminemia & & 0.70 \\
No & $15(14)$ & \\
Yes & $3(18)$ & $\mathbf{0 . 0 0 2}$ \\
NSAID & & \\
No & $13(8)$ & \\
Yes & $8(29)$ & \\
\hline
\end{tabular}

Legend: COPD Chronic obstructive pulmonary disease, ICM lodinated contrast media, NSAID Non-steroidal anti-inflammatory drug, ACE-Inhibitor Angiotensin converting enzyme inhibitor, $N$ Number of patients

determinate number of cycles of cisplatin containing adjuvant or curative chemotherapy. For these patients, a safer administration method such as in-hospital cisplatin administration should be preferred. Transient renal toxicity may also increase health care costs and worsen patients' quality of life. Although we did not perform an analysis to support this, cases developing renal impairment often required supplementary outpatient visits for i.v. hydration or additional hospitalizations.

Cirrhosis was not identified as a predisposing factor for cisplatin-induced renal toxicity before our study. Nonetheless, hypoalbuminemia, a frequent finding in patients with liver damage has been previously described as a predisposing factor [4]. In our study hypoalbuminemia was not predictive of toxicity, but it is important to note that data on albumin levels were missing in $30 \%$ of our cases. As described above, low albumin levels may lead to higher concentrations of free plasma cisplatin, with the potential of increased toxicity. Intriguingly, cirrhotic patients are frequently treated with spironolactone, a drug that increases cisplatin nephrotoxicity as previously described [14].

A high number of cisplatin cycles was previously identified as a risk factor for renal toxicity [15]. In contrast, we found that a number of cisplatin courses equal or lower than 4 was associated with renal toxicity. This could be explained by the fact that cisplatin treatment could have been discontinued early among patients with a worsening renal function, limiting the role of the number of cycles as a patient sorting variable.

We observed that hypertension predisposed patients to a transient renal function impairment. To our best knowledge this has not been previously described. Functional renal vascular abnormalities are observed in hypertensive patients [16]. Subclinical kidney damage 
due to hypertension could constitute a predisposed ground for cisplatin nephrotoxicity.

Strengths of this study include a relatively high number of patients and the large number of variables analyzed.

However, many drawbacks conditioned by the retrospective nature of the study can be pointed-out. On one hand, we could mention the lack of uniformity of the timing for the measurement of creatinine levels, that we selected as the outcome measure. On the other hand, the allocation of comorbidities, such as diabetes, high blood pressure, cirrhosis, etc., which in our study represented some of the independent variables, was based primarily on the information available in the records, that were registered by the treating doctors. Although we sought confirmation of these data from alternative sources, including pathology and laboratory reports or prescription lists, this was not achieved in all cases.

Finally, a more precise grading of the analyzed comorbidities, instead of the assignment of a dichotomous value, such as the characterization of cirrhosis according to the CHILD-Pugh score for example, could have also given further specificity to the results; although, we were unable to collect this information.

\section{Conclusion}

Based on the results of the present study, hypertension and cirrhosis represent risk factors for the development of transient nephrotoxicity in the context of cisplatincontaining chemotherapy treatment. Patients with one or both of these comorbidities may be allowed to receive cisplatin, but more frequent post-therapy planned check-ups of the renal function are recommended. A more aggressive intravenous hydration should be guaranteed whenever a reduction of creatinine clearance of $25 \%$ or more is detected from the beginning.

\section{Abbreviations}

ACE : Angiotensin Converting Enzyme; BMI: Body Mass Index; CNS: Central Nervous System; COPD: Chronic Obstructive Pulmonary Disease; eGFR: estimated Glomerular Filtration Rate; ICM: lodinated Contrast Media; IOSI: Istituto Oncologico della Svizzera Italiana; MDRD: Modification Diet in Renal Disease; N: Number of patients; NSAIDs: Non Steroidal AntiInflammatory Drugs; RT: Radiotherapy; SD: Standard Deviation; VP16: Etoposide

\section{Acknowledgements}

The authors acknowledge the patients and their families.

\section{Authors' contributions}

EG: database, manuscript preparation. AC: database. MG: study design, manuscript preparation. EZ: statistical analysis, study design. LW: study design, manuscript preparation. All authors have read and approved the manuscript.

\section{Funding}

No funding was requested or received for the production of the present study.

\section{Availability of data and materials}

The datasets generated and analyzed during the current study are available from the corresponding author on reasonable request.

\section{Ethics approval and consent to participate}

All procedures performed were in accordance with the ethical standards of the institutional and/or national research committee and with the 1964 Helsinki declaration and its later amendments or comparable ethical standards. The local ethical review board approved this retrospective analysis (Comitato Etico Cantonale, Email address: dss-ce@ti.ch - Web page: https:// www4.ti.ch/dss/dsp/us/ce/comitato/).

\section{Consent for publication}

Not applicable.

\section{Competing interests}

- Dr. Elena Galfetti: no conflicts of interest to declare.

- Dr. Alessandra Cerutti: no conflicts of interest to declare.

- Prof. Michele Ghielmini: no conflicts of interest to declare.

- Prof. Emanuele Zucca: no conflicts of interest to declare.

- Dr. Luciano Wannesson: no conflicts of interest to declare.

\section{Author details}

${ }^{1}$ Kantonsspital Winterthur, Department of Oncology, Winterthur, Switzerland. ${ }^{2}$ Biasca, Switzerland. ${ }^{3}$ Istituto Oncologico della Svizzera Italiana (IOSI), Oncology Clinic, Via Ospedale 12, 6500 Bellinzona, Switzerland.

Received: 26 November 2019 Accepted: 21 February 2020

Published online: 02 March 2020

References

1. Taguchi T, Nazneen A, Abid MR, Razzaque MS. Cisplatin-associated nephrotoxicity and pathological events. Contrib Nephrol. 2005;148:107-21.

2. Arany I, Safirstein RL. Cisplatin nephrotoxicity. Semin Nephrol. 2003;23:460-4

3. Launay-Vacher V, Rey JB, Isnard-Bagnis C, Deray G, Daouphars M. Prevention of cisplatin nephrotoxicity: state of the art and recommendations from the European Society of Clinical Pharmacy Special Interest Group on Cancer care. Cancer Chemother Pharmacol. 2008;61:903-9.

4. de Jongh FE, van Veen RN, Veltman SJ, de Wit R, van der Burg ME, van den Bent MJ, et al. Weekly high-dose cisplatin is a feasible treatment option: analysis on prognostic factors for toxicity in 400 patients. Br J Cancer. 2003; 88:1199-206.

5. Anand AJ, Bashey B. Newer insights into cisplatin nephrotoxicity. Ann Pharmacother. 1993;27:1519-25.

6. Stewart DJ, Dulberg CS, Mikhael NZ, Redmond MD, Montpetit VA, Goel R. Association of cisplatin nephrotoxicity with patient characteristics and cisplatin administration methods. Cancer Chemother Pharmacol. 1997;40: 293-308.

7. Daugaard G. Cisplatin nephrotoxicity: experimental and clinical studies. Dan Med Bull. 1990;37:1-12.

8. Daugaard G, Abildgaard U, Holstein-Rathlou NH, Bruunshuus I, Bucher D, Leyssac PP. Renal tubular function in patients treated with high-dose cisplatin. Clin Pharmacol Ther. 1988:44:164-72.

9. Hartmann JT, Fels LM, Franzke A, Knop S, Renn M, Maess B, et al. Comparative study of the acute nephrotoxicity from standard dose cisplatin +/- ifosfamide and high-dose chemotherapy with carboplatin and ifosfamide. Anticancer Res. 2000;20:3767-73.

10. Madias NE, Harrington JT. Platinum nephrotoxicity. Am J Med. 1978; 65:307-14

11. Haas A, Anderson L, Lad T. The influence of aminoglycosides on the nephrotoxicity of cis-diamminedichloroplatinum in cancer patients. J Infect Dis. 1983;147:363.

12. Mathe C, Bohacs A, Duffek L, Lukacsovits J, Komlosi ZI, Szondy K, et al. Cisplatin nephrotoxicity aggravated by cardiovascular disease and diabetes in lung cancer patients. Eur Respir J. 2011;37:888-94.

13. Daugaard G, Abildgaard U. Cisplatin nephrotoxicity. A review. Cancer Chemother Pharmacol. 1989;25:1-9.

14. Ahmida MH, Abdel-Gayoum AA, El-Fakhri MM. Effect of spironolactone on cisplatin-induced nephrotoxicity in rabbits. Hum Exp Toxicol. 2001;20:453-9. 
15. Yao X, Panichpisal K, Kurtzman N, Nugent K. Cisplatin nephrotoxicity: a review. Am J Med Sci. 2007;334:115-24.

16. Hollenberg NK, Adams DF, Solomon H, Chenitz WR, Burger BM, Abrams HL, et al. Renal vascular tone in essential and secondary hypertension:

hemodynamic and angiographic responses to vasodilators. Medicine (Baltimore). 1975;54:29-44.

\section{Publisher's Note}

Springer Nature remains neutral with regard to jurisdictional claims in published maps and institutional affiliations.

Ready to submit your research? Choose BMC and benefit from:

- fast, convenient online submission

- thorough peer review by experienced researchers in your field

- rapid publication on acceptance

- support for research data, including large and complex data types

- gold Open Access which fosters wider collaboration and increased citations

- maximum visibility for your research: over $100 \mathrm{M}$ website views per year

At $B M C$, research is always in progress.

Learn more biomedcentral.com/submissions 